\title{
Editorial
}

\section{An end to violence?}

The choice of the topic of violence for the 1979 Conference of the London Medical Group is a significant one. Increasingly doctors and other health service workers are becoming aware of the social context of medicine. Violence is an apparently inescapable feature of that context. At an obvious level, violence in society manifests itself daily in Accident/Emergency Departments, the phenomenon of child battery being a particularly horrifying example. But violence also has subtler effects on the incidence of disease and disability. Road traffic accidents, mental disturbance and the numerous diseases provoked by stress can all be seen as, in part, the products of a society which generates a destructiveness blindly seeking an outlet in violence against self or others.

It is a pity that in a topic area of such importance there seems little or no agreement among psychologists and sociologists about the origins of violence in society or the ways of dealing with it. Nowhere perhaps is the 'nature versus nurture' debate seen more clearly. The papers published in this issue by Professor Eysenck and Dr and Mrs Russell illustrate this well.

Eysenck, despite an avowed catholicity of view, sees effective social conditioning against violence as the main answer: the Russells believe that the solution lies in the provision of more social space to prevent it occurring. Meanwhile harassed ward sisters like Sylvia Winterbottom wonder how they can help their staff to cope with the chaos and aggressiveness which invades their hospitals each weekend: and Jan Pahl asks how women who are regularly beaten by their husbands can gain relevant assistance from the medical and social work professions. It seems that the 'sciences of man' are still too speculative and inexact to offer many practical solutions to educators, legislators and, in particular, to those who deal daily with the general public in a service capacity.

Is any discussion of the problem, then, a pointless activity? Not necessarily. Human beings always find themselves the hardest part of nature to understand and have spent countless generations puzzling over the mystery. It is possible, of course, to take the jaundiced view that violence will always be a feature of human societies, and that no amount of social reform will make it otherwise. (Authorities as diverse as St Augustine and Sigmund Freud would endorse this viewpoint!) Against this, we can only hope for an increase in self-awareness emerging $\vec{\omega}$ from an honest, comprehensive and persistent discussion of violence in all its aspects. Violence, we must realise, is not a characteristic of some alien group 'out there' in the back streets, the football $\dot{\omega}$ terraces or the homes of the underprivileged. $\vec{\theta}$ Violence is in us, in our bodies, stifled perhaps, or channelled in socially useful activities or turned against ourselves in illness and guilt, but there nonetheless. To acknowledge its omnipresence could well be the first step in its undoing:

Ye suffer from yourselves, none else compels None other holds you that ye live and die And whirr upon the wheel, and hug and kiss Its spokes of agony. ${ }^{1}$

\section{BMA Ethical Handbook}

In April of this year the Ethical Committee of the British Medical Association produced a draft of a new Handbook of Medical Ethics. The desire to revise the existing Handbook is certainly to be welcomed, since it reflects the feeling that professional ethics should be more than rules of etiquette designed primarily for the protection of the profession's status within society. The new document begins with a very brief history of 3 . medical ethics and then deals with its subject matter under three main headings: Relationships between Doctors and Individuals; Relationships $O$ between Doctors and Groups; Etiquette, Professional Discipline, the Law and Codes of Practice. This framework allows a very wide range of subjects to be discussed ranging from confidentiality $\mathcal{N}$ to industrial action by doctors. The document alson contains a useful appendix in which several examples N of codes and declarations by the WMA and by various national associations are printed.

Since at the time of writing this draft has still to be considered by the annual representatives' meeting? of the BMA and has been sent to other bodies for comment, it would be inappropriate to discuss it in detail. (When the final text is published wed intend to offer an extensive review.) The draft 
suffers from the predictable weaknesses of a document compiled by a committee from a variety of individual submissions. The division of the subject matter, the use of headings and the relative length of sections all require critical scrutiny. Such unevenness of presentation may also reflect the fact that the present draft falls between two stools: it is neither a fully developed discussion of the highly complex issues now arising in medical ethics, nor is it (as its title might suggest) a simple compendium of guidance to practitioners on matters about which there is no disagreement within the profession. Perhaps it is unrealistic to expect a professional organisation to produce anything which questions too radically the basis upon which it currently $\frac{c}{\zeta}$

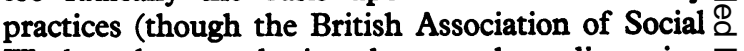
Workers has not hesitated to produce discussion 1 documents of this nature). The BMA Ethical Committee is certainly to be commended for its? willingness to move a little from the safe waters of prescriptive ethics to the storms of contemporary medical dilemmas.

\section{Reference}

${ }^{1}$ Watts, A (1976). The wisdom of insecurity. London, $\vec{O}$ Rider \& Co., p. 136. 